\title{
Estéticas do Abandono
}

Aesthetics of Abandonment

\section{LUCAS GERVILLA}

Universidade estadual paulista (UNESP) SÃO PAULO, Brasil

\section{RESUMO}

Estéticas do Abandono é um ensaio visual contendo doze imagens, feitas entre os meses de março a dezembro de 2020, que registram lugares abandonados: a Usina Hidrelétrica Dr. Geraldo Tosta em Bragança Paulista, a fábrica de panelas Trofa L em Campo Limpo Paulista e o campo de bocha do Parque da Aclimação na cidade de São Paulo. Construções que um dia significaram avanços sociais ou tecnológicos e, atualmente, vivem um estado ruinoso presente. $\bigcirc$ trabalho faz parte da atual pesquisa de doutorado do artista, em desenvolvimento no Instituto de Artes da Unesp.

\section{PALAVR A S - C H AVE}

Lugar abandonado, Memória, Ruína.

\begin{abstract}
A B S T R A C T
Aesthetics of Abandonment is a visual essay with 12 images, made between March and December of 2020 that depict three abandoned places: the hydroelectric power plant Dr. Geraldo Tosta in Bragança Paulista, the cookware factory Trofa in Campo Limpo Paulista, and a bocce ball field in São Paulo city. Constructions that once meant social and economic progress, however, nowadays are living a constant ruinous present. The work is part of the artist's current doctoral research under development at the Institute of Arts at Unesp.
\end{abstract}

\section{KEYWORDS}

Abandoned place, Memory, Ruin. 

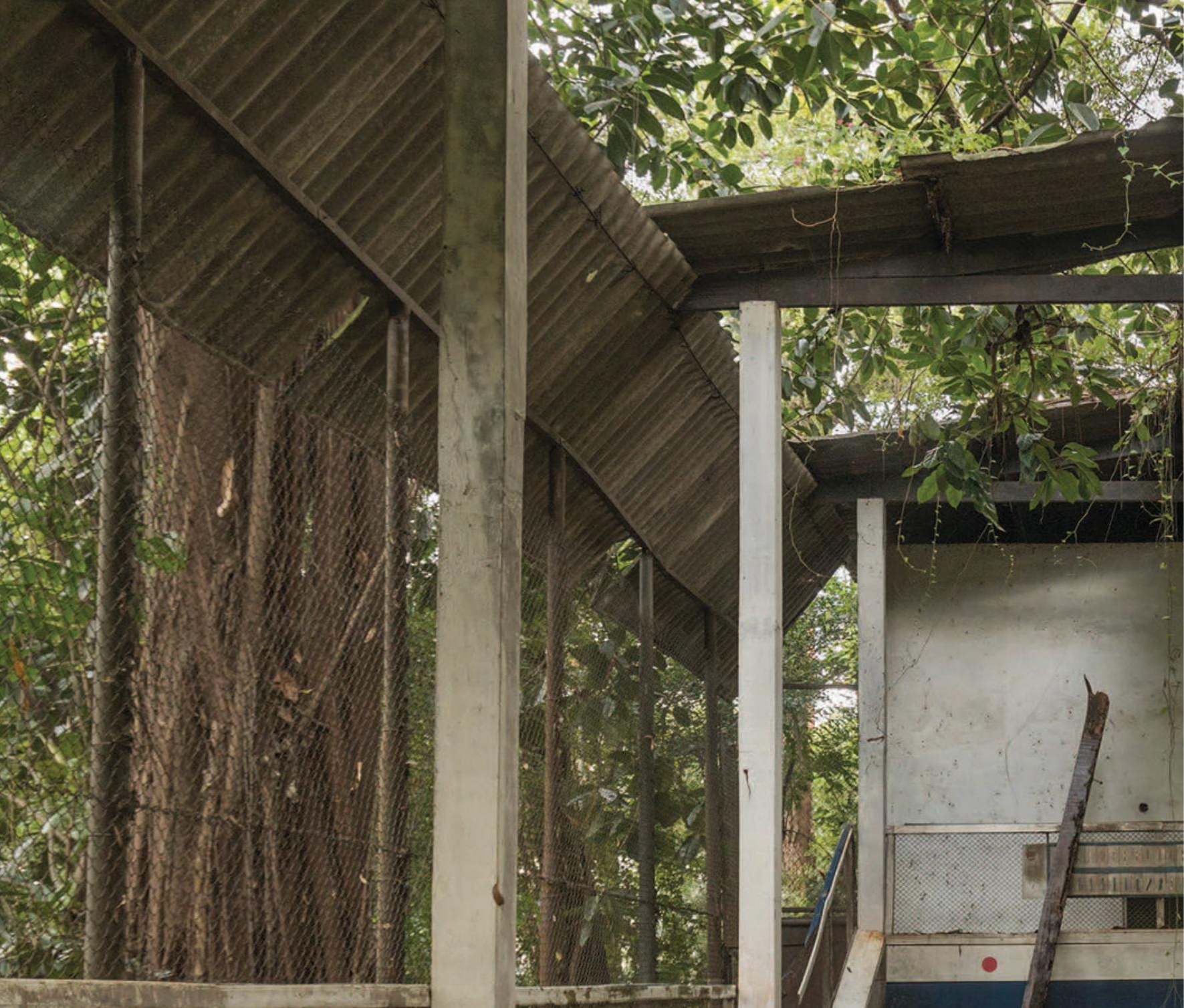


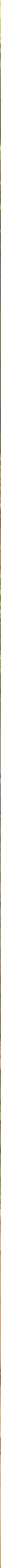



42
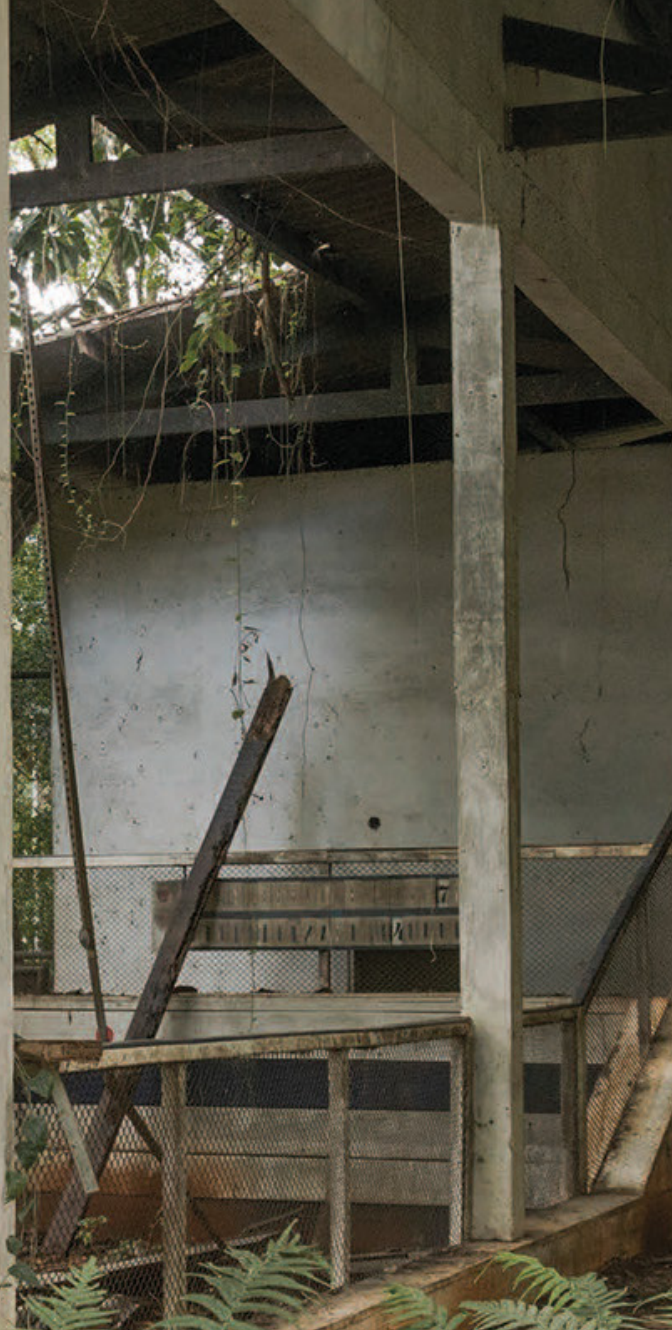


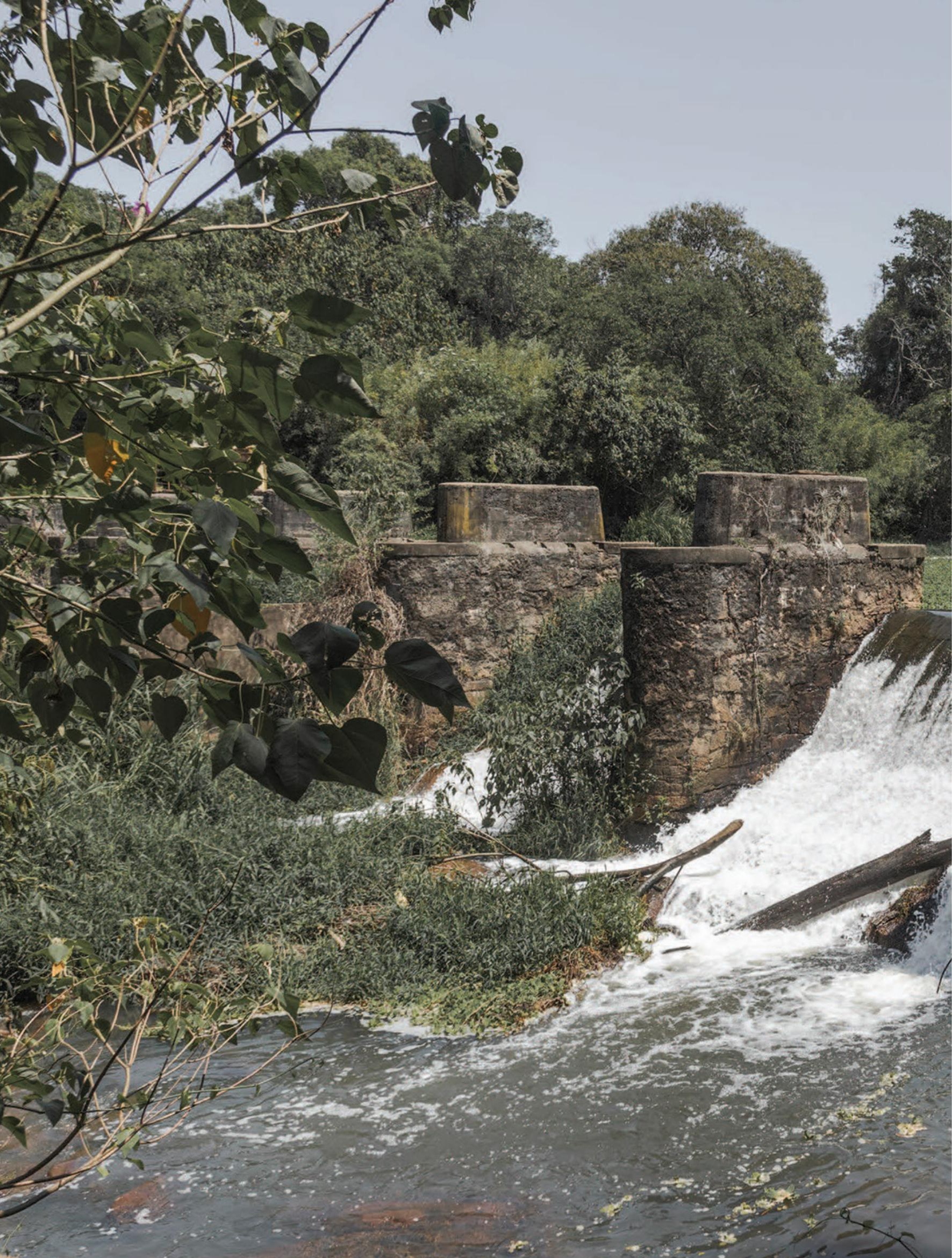




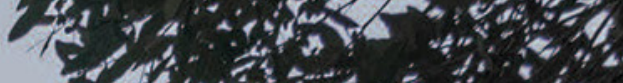

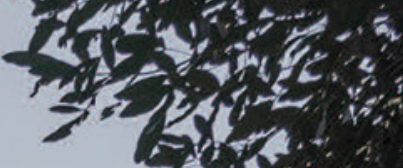

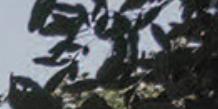

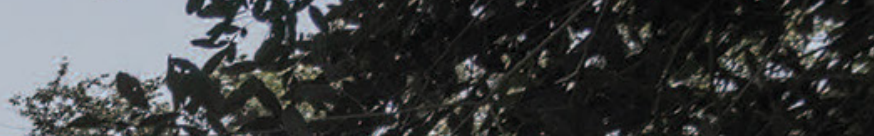

k.

W.
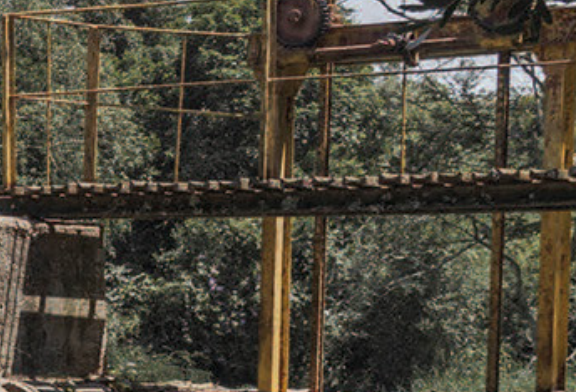

in

k. 17,4

2.

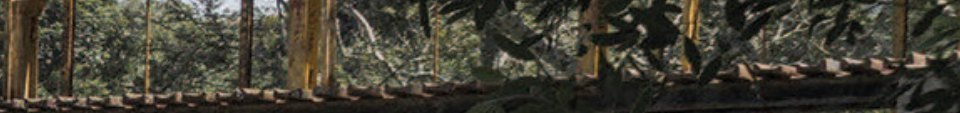

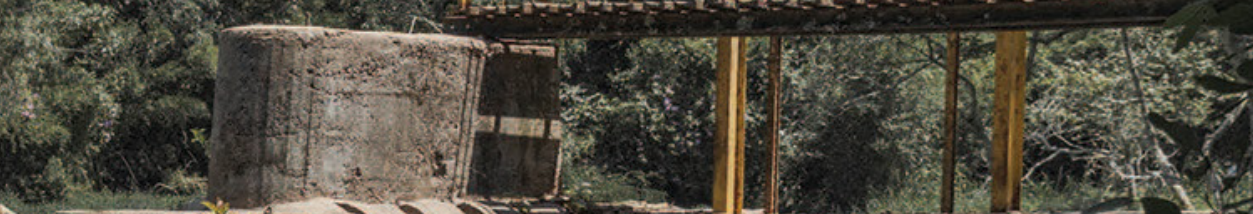

som -2

4xte. 201

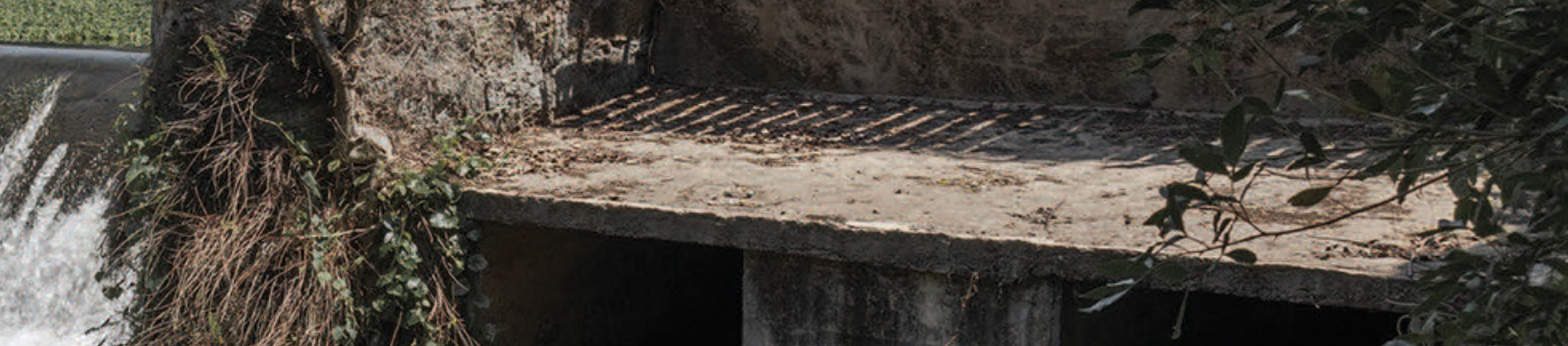

3 (1)

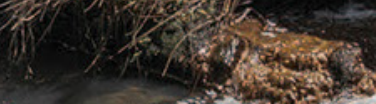

$\rightarrow x^{2}$
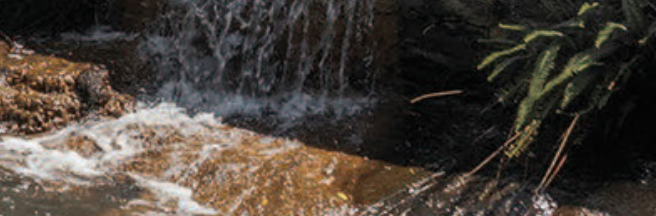

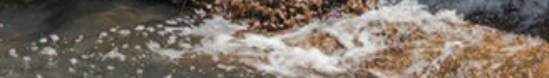
-

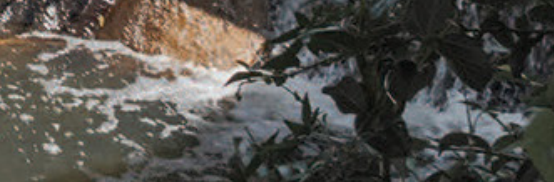

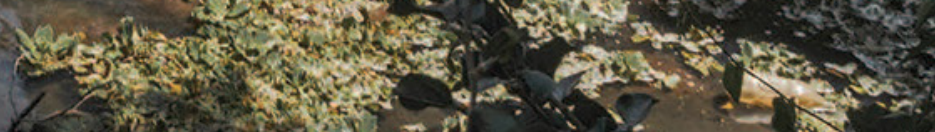




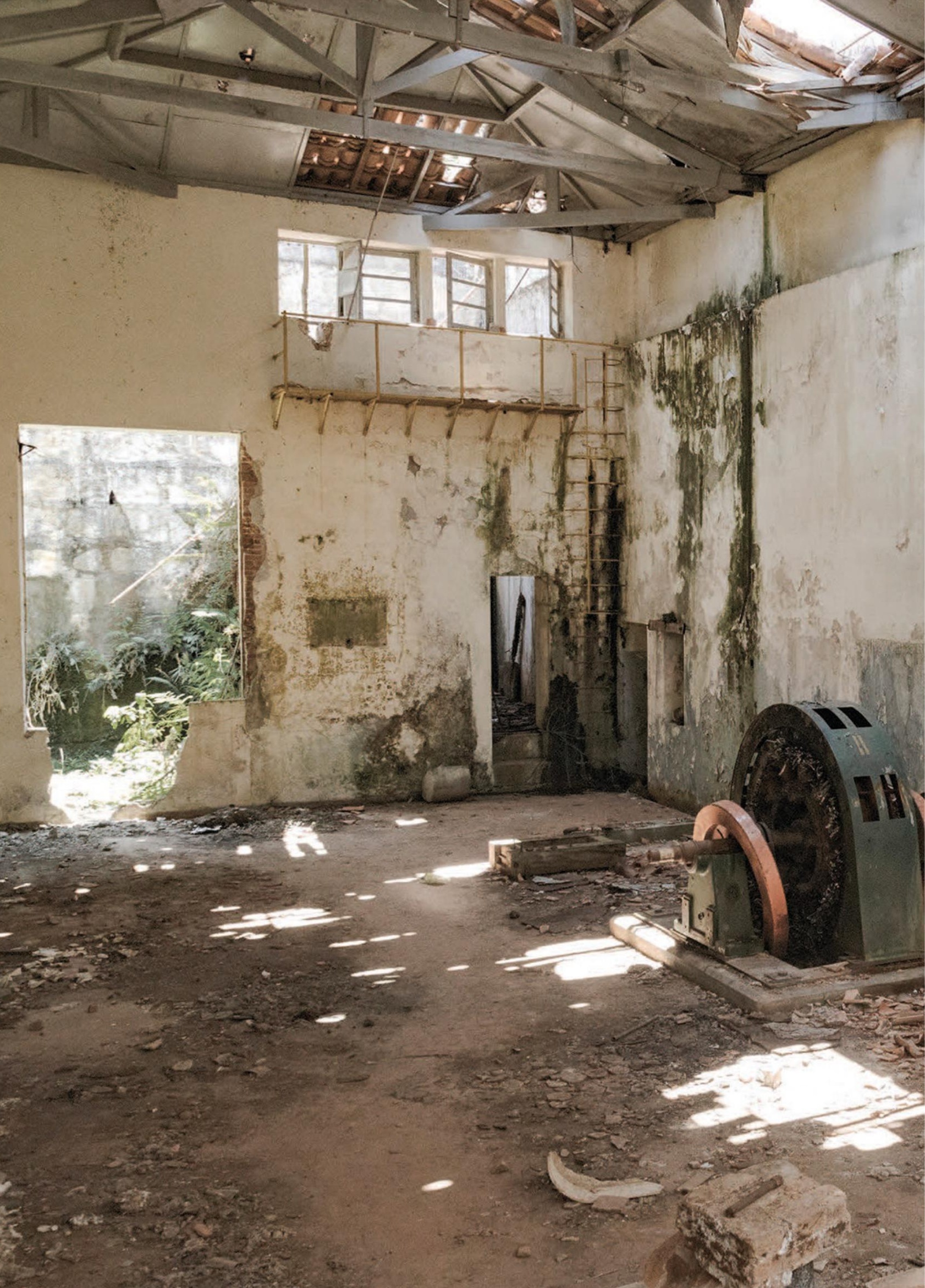





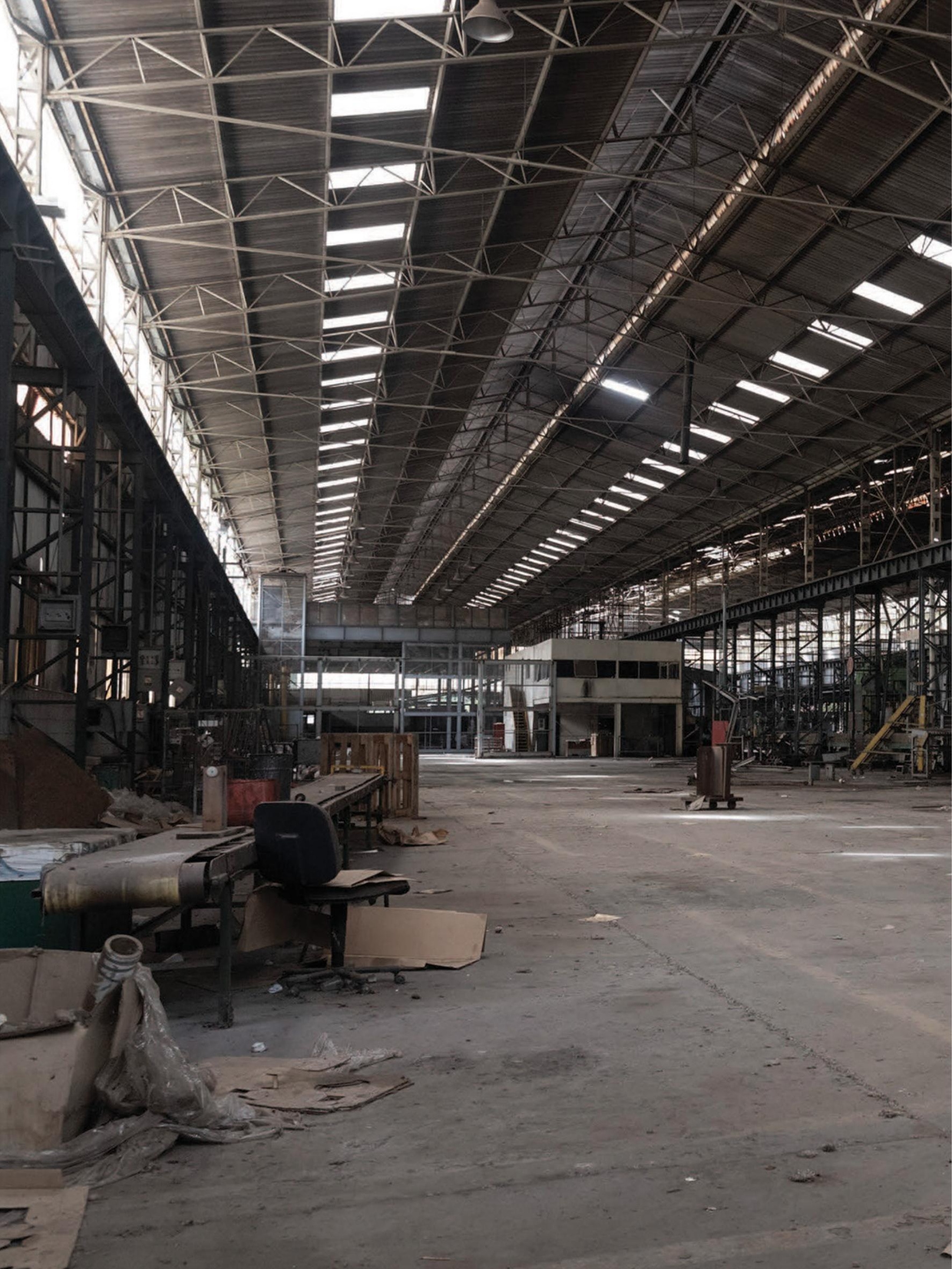




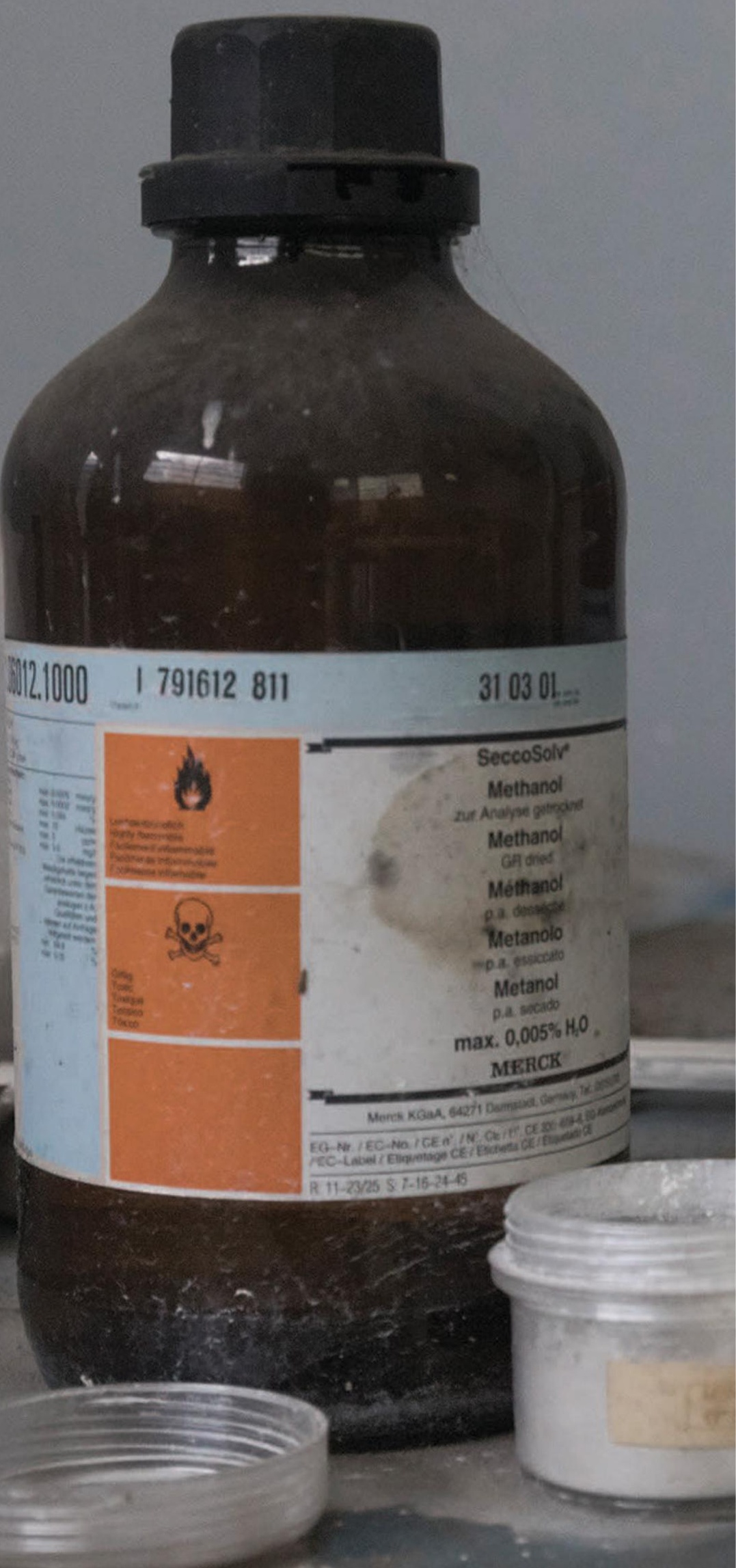




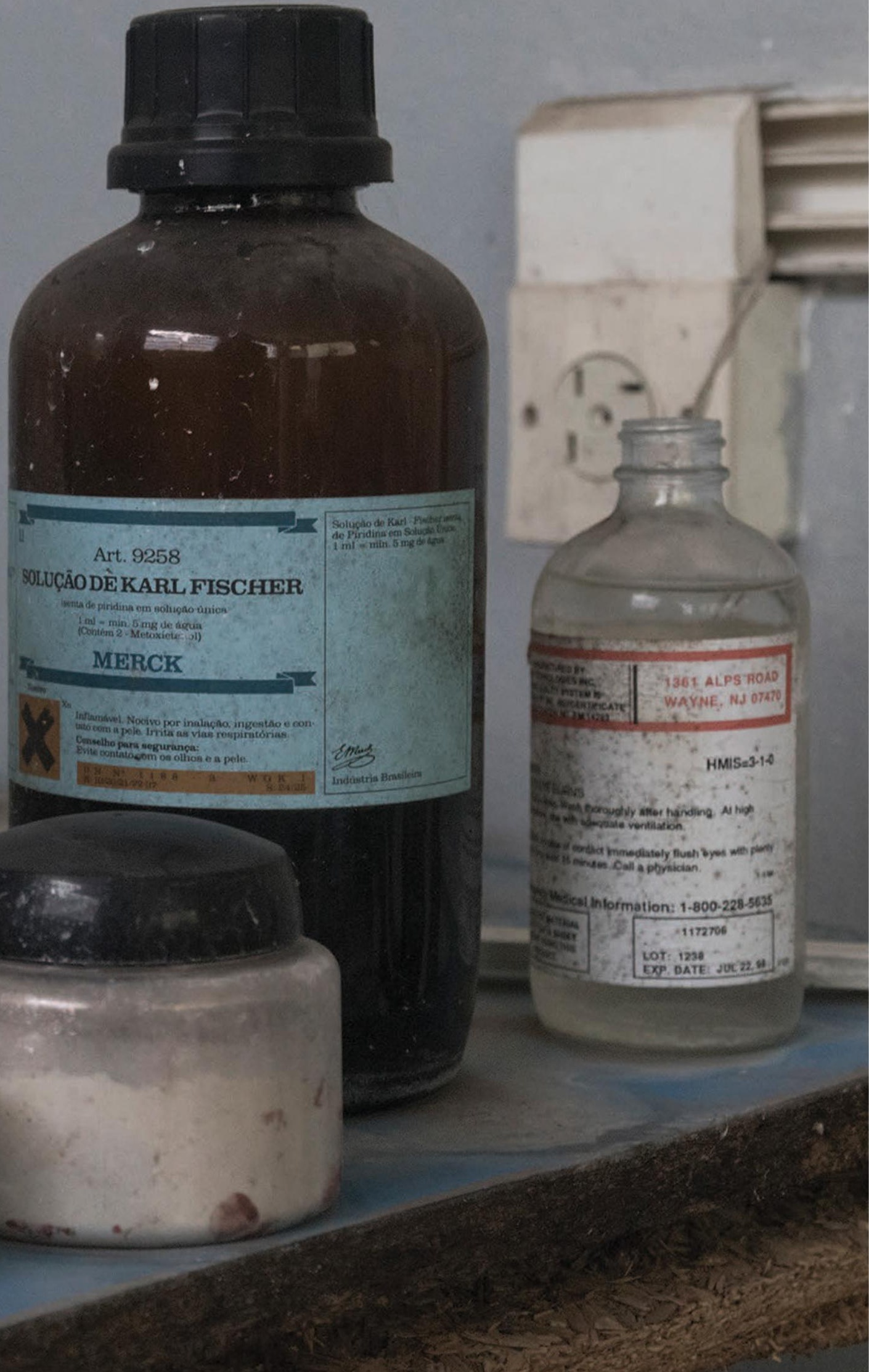




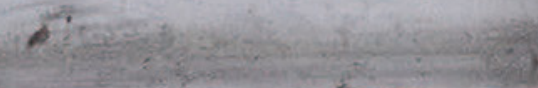

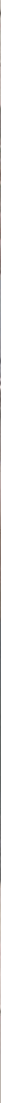


a.

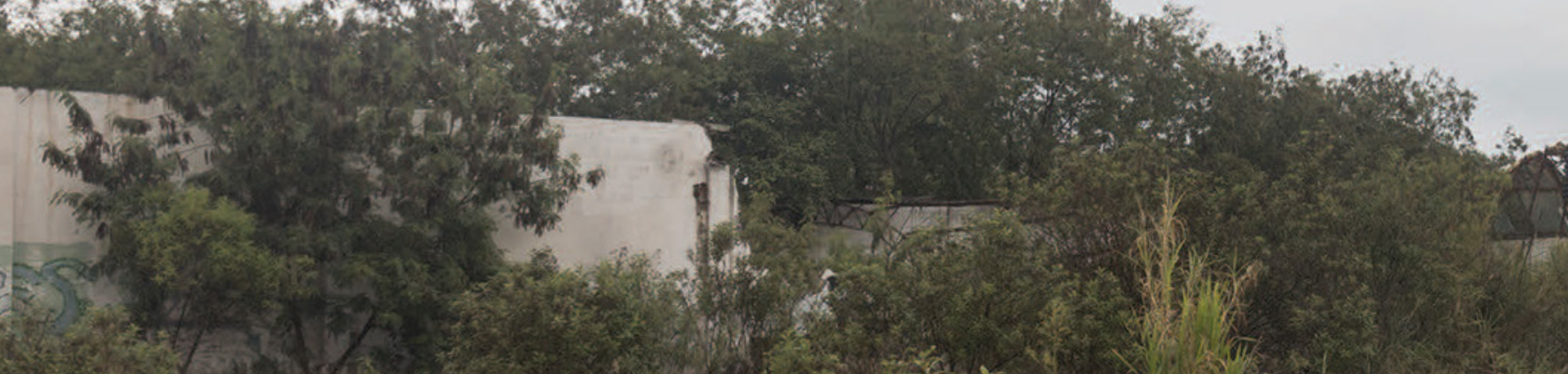

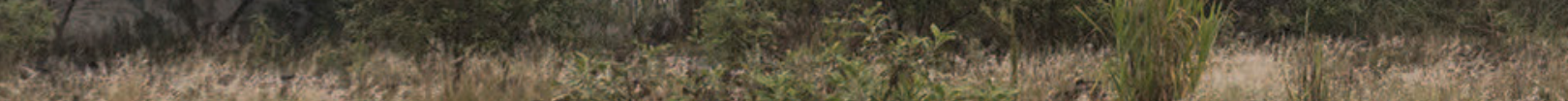

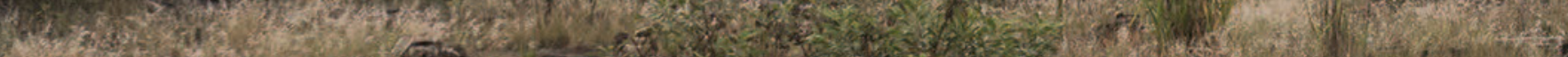

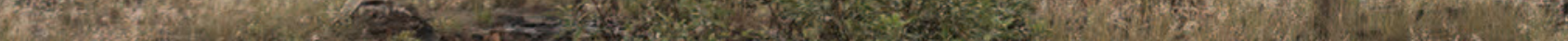
to r. 20.

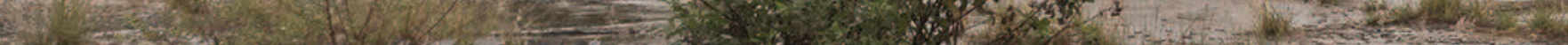

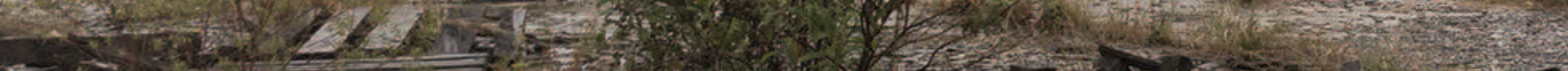

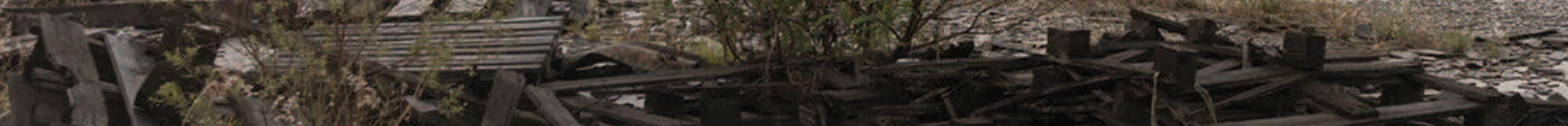

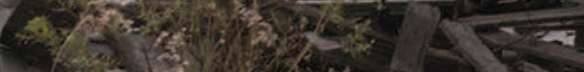

\section{(2)}




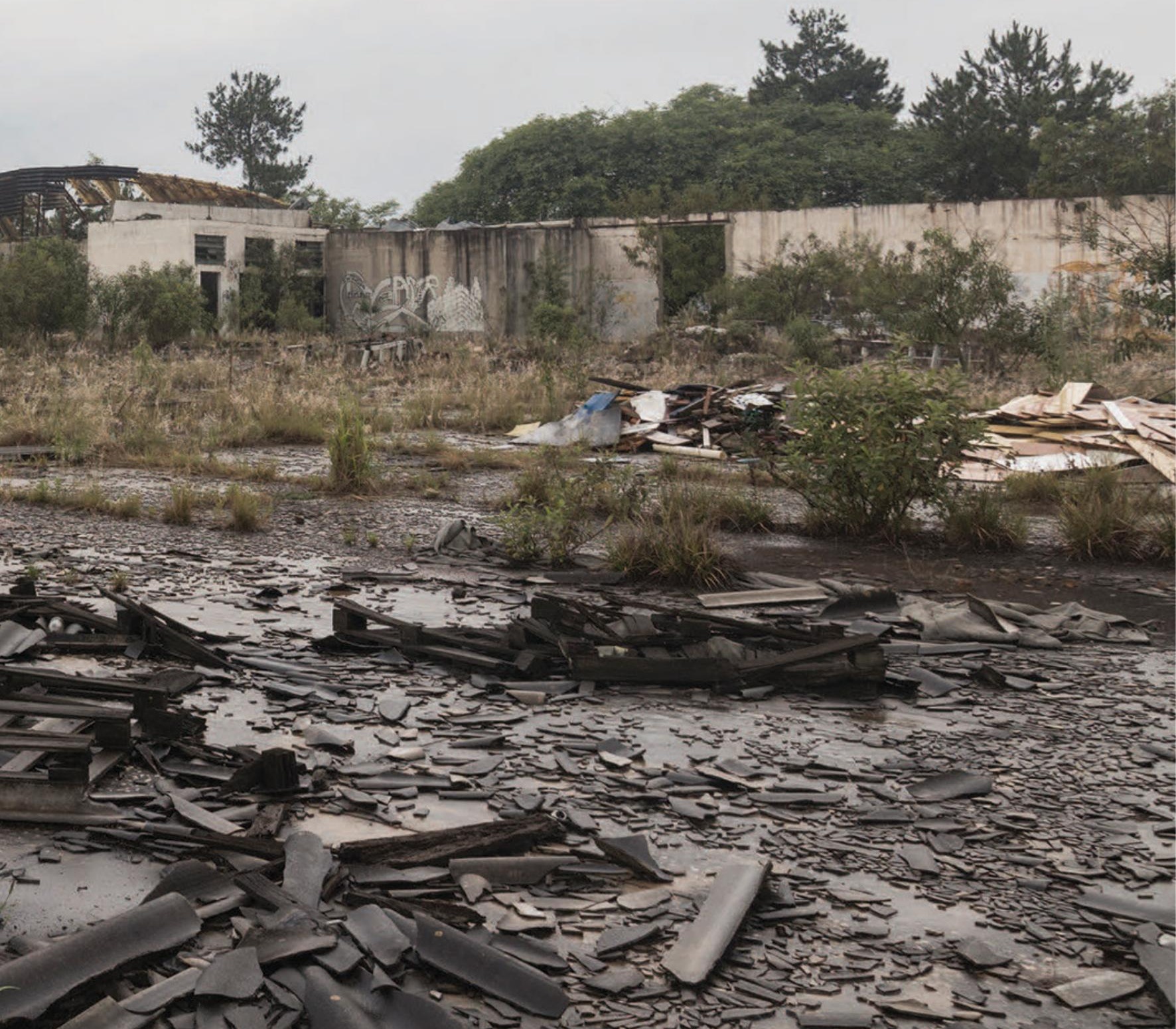




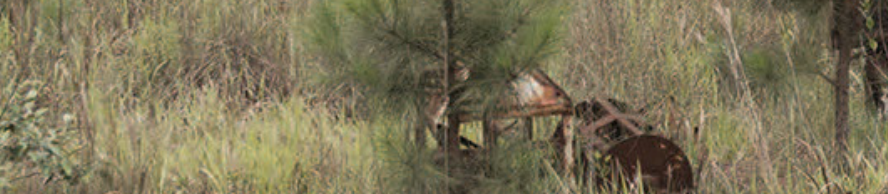<smiles></smiles>

10.

\section{griss.} - $25 x=$

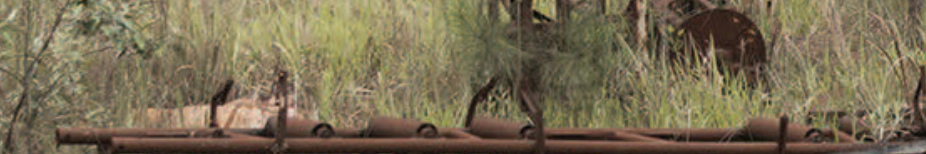




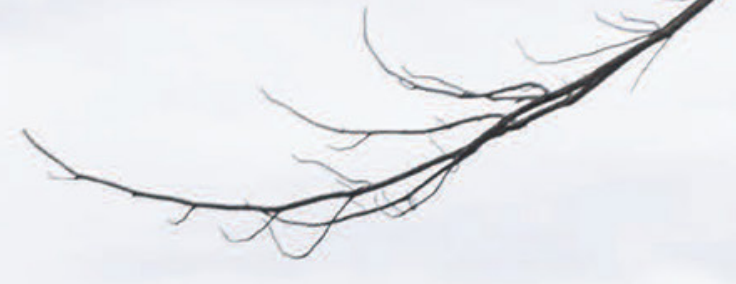





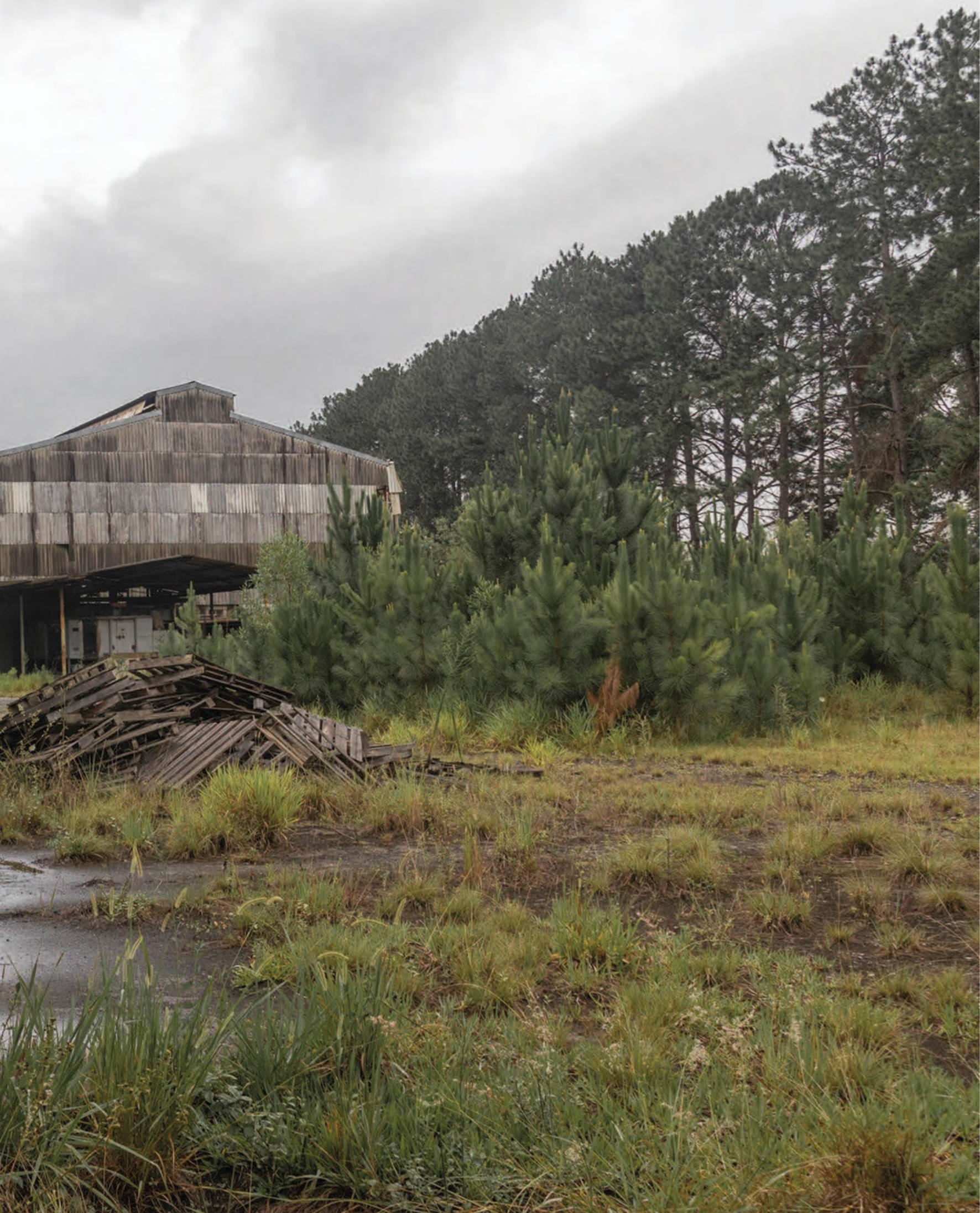




\section{Sobre o autor}

Lucas Gervilla é artista visual, trabalha com imagens desde 2005. Doutorando e mestre pelo Instituto de Artes da UNESP e bacharel em Comunicação e Multimeios pela PUC-SP. Participou de mais de 160 produções artísticas. Dirigiu os longa-metragens Ruinoso e Fora da Capital. Em 2017 recebeu a bolsa "Mobility Fund" oferecida pelo Prince Claus Fund.

LATTES: http://lattes.cnpq.br/4985531457212451

ORCID: https://orcid.org/oooo-0002-4423-0137

SITE: www.gerva.me

\section{Como citar}

GERVILLA, Lucas. (2021). Estéticas do abandono. Revista Estado da Arte, Uberlândia. v.2, n.1, p. 309-334, jan./jun. 2021. https://doi.10.14393/EdA-v2-n1-2021-59210 